\title{
Evaluation of RAST inhibition as a method for the standardization of house-dust extracts* $†$
}

\author{
P. L. B. Bruynzeel, $\ddagger W$. Kersten $\$$ \\ and L. Berrens $9 \|$
}

RAST-inhibition was evaluated as a method for the in vitro standardization of house dust allergens, using four lyophilized house-dust preparations of different degree of purification $\left(R_{1}\right.$, $R_{2}, R_{3}$ and $R_{4}$ ). When a serum pool of highly house-dust sensitive patients was used, a qualitatively similar potency sequence by RAST-inhibition between the different preparations could be established as with in vivo skin testing. When, however, individual sera were examined, striking differences were observed in both the qualitative and the quantitative potency relationships. Furthermore, large variations were noted in duplicate measurements in RAST-inhibition.

From this study it became clear that in vitro RAST inhibition and in vito skin tests can have only statistical meaning for the standardization of house-dust allergen. In individual parients, striking differences may occur in the response to different preparations, thereby making standardization by these techniques rather unsatisfactory. By applying these techniques, we gained the impression that patients were being characterized rather than allergens.

\section{INTRODUCTION}

Although standardization of the biological activity of allergenic extracts used in

- Received for publicarion 9 July 1979.

$\uparrow$ This study forms part of a multicenter project on the standardization of house dust allergens, which will be covered in full detail in future communications.

$\ddagger$ Departments of Pulmonary Disease, Academic Hospital, Uttecht, The Netherlands.

5 Experimental Allergy, Academic Hospital, Utrecht, The Netherlands.

I Krankenhaus Bethanien, Department of Allergy, Moers, Federal Republic of Germany.

\|l Correspondence to: L. Berrens, Ph.D., Department of Dermatology, Division of Experimental Allergy, University Hospital, Catharijnesingel 101. Utrecht, The Netherlands.

$0092-1157 / 80 / 010069+10 \$ 02.00 / 0$

(C) 1980 The International Association of Biological Standardization 
humans has been recognized as a problem for a good many years, the subject has recently been getting increased actention-for reasons of legislation. It is now generally agreed that the methods commonly used for indicating extract potency may be very unrealistic, i.c. weight per volume, total nitrogen, or protein-nitrogen units (PNU). A long time ago, Arbesman \& Eagle (1939) already demonstrated that none of these potency measurements correlated with the biological activity of allergenic extracts as determined by in virro neurralizacion of reagins.

The development of the radioallergosorbent technique (RAST) has provided a method of measuring $\operatorname{lgE}$ antibody in, vitro (Wide, Bennich $\&$ Johansson, 1967) and, recently, several investigators have employed either direct RAST or RAST-inhibition for the in vitro standardization of various allergens (Arbesman, Wypych \& Reisman, 1977; Ceska, Eriksson \& Varga, 1972; Gleich, Larson, Jones \& Baer, 1974; Yman, Ponterius \& Brandt, 1975). However, no attempts have been published so far to standardize the widely used house dust extracts by means of this particular technique. A major reason may be the rather poor correlations reported between the results of in wito skin testing and in vitro RAST assay (Aas \& Johansson, 1971; Hogarth Scott, McNicol, Williams \& Johansson, 1973; Kersten, 1978; Pascual et al., 1977; W/üchrich \& Kopper, 1975 ).

The study of house dust allergens and their modes of action has led to the proposal that these substances may exert considerable non-immunological activity as enzymeactivaring agents (Berrens, 1974). This activity is reflected in the complementconsuming capacity of purified house dust allergens, which has been suggested as a possible means of in vitro standardization (Berrens \& Guikers, 1974).

It was the aim of the present multicenter investigations to evaluate the various now available techniques for the in vitro and in vivo standardization of house dust allergens. For this purpose, four house dust allergen preparations of different provenance and different degree of purification were obtained and submitted to Institutes in various parts of the world. The present paper documents the data on RAST inhibition in relation to skin test results with these various preparations.

\section{MATERIALS AND METHODS}

Sera

Blood samples were obtained from patients with atopic diseases attending the Out-pacient Departments of Pulmonary Disease and Clinical Allergy at the Utrecht University Hospital. The samples were clotted in glass and the sera, obtained by centrifugation, were stored at $-70^{\circ} \mathrm{C}$ until use. For serum pools, the samples of a minimum of 15 highly house dust-allergic patients were combined. Serum pools were used as standard references for the RAST inhibition studies.

\section{Allergens}

The house dust preparations used in this investigation were coded $R_{1}-R_{4}$ and were obrained as follows:

$R_{1}$ was a partially purified preparation from a large lot of combined vacuum cleaner dust, purified to the stage by fraction $C$ according to a published schedule (Berrens, 1970). The preparation was prepared and kindly donated by Haarlems Allergenen

Laboratorium b.v., Haarlem, The Netherlands (batch $\mathrm{H}-772$ ). 
$R_{2}$ was obtained as a relatively crude, benzoic acid adsorbed A-fraction (Berrens, 1970) from a pool of dust obcained from an ultra-modern hotel in the Utrecht area, where absolutely no pets (cats and dogs) were allowed. From this product, a highly purified product $R$, was prepared by pursuing the schedule to fraction $E$ (Berrens, 1970), followed by Sephadex G75 gel filtrarion and collection of the first peak off the column.

Finally, the $R_{3}$-preparation was secured from house dust collected in Paris, France, and purified by ammonium sulphate precipitation as described (Laroche, Ky, Relyveld \& Roche, 1967). It was kindly submitted by Dr E. H. Relyveld as a $25 \mathrm{ml}$ solution Poussière de Maison Concentrée. lot no. 8 , staced to have $0.318 \mathrm{mg}$ $\mathrm{N} \mathrm{ml} \mathrm{m}^{-1}$, i.e. 31800 .units $\mathrm{ml}^{-1}$

All preparations were dialysed and dried by lyophilization. The details of analytical investigarions by physicochemical means will be published elsewhere.

\section{Allergen paper discs}

For the estimation of IgE antibody and for RAST-inhibition, $R$, discs were prepared by coupling $10 \mathrm{mg}$ of $R_{1}$ with cyanogen bromide to Whatman no. 1 filcer paper discs (100 discs, weighing about $300 \mathrm{mg}$ ), according to the method of Ceska, Eriksson \& Varga (1972). A similar procedure was followed to couple product $R_{4}$. Furthermore, discs were prepared in London according to the NIBSC method, using British house dust preparations $\mathrm{Gpl}$ mixture of acetone and $\mathrm{pH} 3$ fractions as described (Brighton \& Topping, 1977).

\section{Radioallergosorbent tests (RAST)}

The direct RAST. was performed according to instructions of the manufacturer of the anti IgE reagent (Pharmacia Diagnostics AB, Uppsala, Sweden) with minor modifications. Serial dilutions of the serum pool were examined prior to RAST-inhibition experiments in order to determine the optimal dilution to be used in regular RASTinhibition. The latter was performed essentially according to Arbesman, Wypych \& Reisman (1977). Serial dilurions of each of the inhibiting preparations $\left(R_{1}, R_{2}, R_{33}, R_{4}\right)$ in $1 \%$ human serum album in (HSA) were prepared, and $150 \mu \mathrm{l}$ samples were broughe in duplicate rows of 11 or more polystyrene test tubes. The last tube in each row contained $1 \%$ HSA only; $50 \mu \mathrm{l}$ aliquots of the optimal dilution of the reference serum pool (or of individual sera) were then added to each tube. The mixture was shaken vigorously and left at room temperature overnighr. A disc coupled with allergen $\left(R_{1}\right.$, $R_{4}$ or $G_{p_{1}}$ ) was then added to each tube and the tubes were left at room temperature for $20 \mathrm{~h}$. After three washings with $2 \mathrm{ml}$ of saline and removal of the supernatants by suction, $50 \mu \mathrm{I}$ of radiolabelled rabbit anti human $\mathrm{gE}$ was added, and the rubes were capped, carefully shaken and left at room temperature overnight. After three additional washings with saline $(2 \mathrm{ml})$, radioactivity bound to the discs was measured in a $\gamma$-councer. The results were expressed as percent inhibition, i.e.

$$
100 \times \frac{\% \text { RAST score }+ \text { inhibitor }}{\% \text { RAST score - inhibitor }} \text {, where } \% \text { RAST score }
$$

represents the activity bound by the allergen-disc after incubation with serum as percent of the total radioactivity added to the test system. RAST scores were corrected 
for aspecitc binding of radioactive anti IgE to the disc in the presence of $1 \% \mathrm{HSA}$. The quanticy of house dust preparation required for $50 \%$ RAST-inhibition was evaluated in terms of weight from logarichmic plots.

\section{Skin iests}

These were performed by the intracutaneous route in the skin of the back of house-dust sensitive patients visiting the Hospital Bethanien, Department of Allergy at Moers, using $0.05 \mathrm{ml}$ of 10-fold serial dilutions of $R_{1}-R_{+}$in phosphate buffered saline. Concentrations ranged from $0.0 .4-400 \mu \mathrm{g} \mathrm{ml}^{-1}$. For endpoint titration in vivo, a $7 \mathrm{~mm}$ wheal was empirically chosen as the end point. In case the original endpoint was negative, sequentially stepped-up concentrations were used until a definite response was obrained.

\section{RESULTS}

\section{RAST-inbibition}

The four house dust preparations under investigation, $R_{1}-R_{4}$, were examined for their capacity in RAST-inhibition. An illustration of actual data obtained in a typical RAST-inhibition experiment, using $R_{1}$ paper discs, a serum pool, and the homologous $R_{1}$ product for inhibition is recorded in Table 1.

These results clearly demonstrate that large variations were obtained in duplicate measurements. This implies that the determination of the $50 \%$ inhibition point will be rather inaccurate. Although Arbesmanet al. (1977) and Yman et al. (1975) consider a duplicate variance of about $15 \%$ acceptable, it is obvious that such variances prohibit the correct discrimination of extracts with only slightly different potencies. Neverthe-

TABLE 1. Typical experimental data: inhibition of $R_{1}$ house-dust RAST

by the homologous house-dust preparation $R_{1}$ using a serum pool of house-dust sensitive patients

\begin{tabular}{|c|c|c|c|c|c|}
\hline $\begin{array}{c}\text { Inhibiting } \\
R_{1} \text {-concentration } \\
\text { in } \mu \mathrm{g}\end{array}$ & \multicolumn{2}{|c|}{ Net counts $4 \min ^{-1 *}$} & \multicolumn{2}{|c|}{ Percent bound $†$} & $\begin{array}{c}\text { Mean } \\
\text { inhibitiont }\end{array}$ \\
\hline 100 & 14035 & 12589 & $43 \cdot 3$ & $36 \cdot 4$ & $60 \cdot 2$ \\
\hline 50 & 13436 & 12302 & $40 \cdot 4$ & $35 \cdot 1$ & $62 \cdot 3$ \\
\hline 15 & 12294 & 10818 & $35 \cdot 1$ & $27 \cdot 9$ & $68 \cdot 5$ \\
\hline 5 & 11758 & 12114 & $32 \cdot 6$ & $34 \cdot 2$ & $66 \cdot 6$ \\
\hline $1 \cdot 67$ & 15146 & 18337 & $48 \cdot 6$ & $64 \cdot 0$ & $43 \cdot 7$ \\
\hline 0.56 & 18900 & 20770 & $66 \cdot 8$ & $75 \cdot 6$ & $28 \cdot 8$ \\
\hline 0.19 & $24 \quad 132$ & 21015 & $93 \cdot 8$ & $76 \cdot 8$ & $15 \cdot 7$ \\
\hline 0.06 & 23437 & 22956 & $88 \cdot 4$ & $86 \cdot 2$ & $12 \cdot 7$ \\
\hline $1 \%$ HSA & 23906 & 27506 & - & - & 0 \\
\hline
\end{tabular}

- These counts we re correcred for background; 1 and 2 refer to duplicate samples.

+ Amount of $1 \mathrm{gE}$ antitxody not neutralized by $R_{1}$ and still available to bind גati-1,E.

: Obrained by suberacting the mean percent bound (average of duplicates) from $100 \%$. 
less, the results do have some significance, because the duplicares show a certain reproducibility.

For the comparison of preparations $R_{1}, R_{2}, R_{3}, R_{4}$ and the British Gp product, dose-response curves for RAST-inhibition were composed, using different human sera and discs coupled to either $R_{1}, R_{4}$ or $G p_{1}$. Some cypical inhibition curves are shown in Figs $1,2,3$ and 4 . Figures 1 and 2 demonstrate that the same sequence of inhibiting power $R_{1} / R_{2} / R_{4}$ is found in a single individual serum when discs coupled with house dust preparations of different origin and degree of purification are used. As also discussed below, this indicates that the potency sequence found in a single serum does not seem to depend on the allergen preparation coupled to the disc. However, the results may be dependent on the serum sample used, as illustrated in Fig. 3, where the same sequence of inhibition potency was found as in Fig. 1, but where the pattern of the curves was quite different owing to a change of serum.

The choice of the serum sample used may, however, also affect the potency sequence found among different preparations. This is illustrated in Fig. 4, which depicts the RAST-inhibition curves of $R_{1}, R_{2}, R_{3}$ and $R_{4}$ using a pool of sera of Dutch house dust

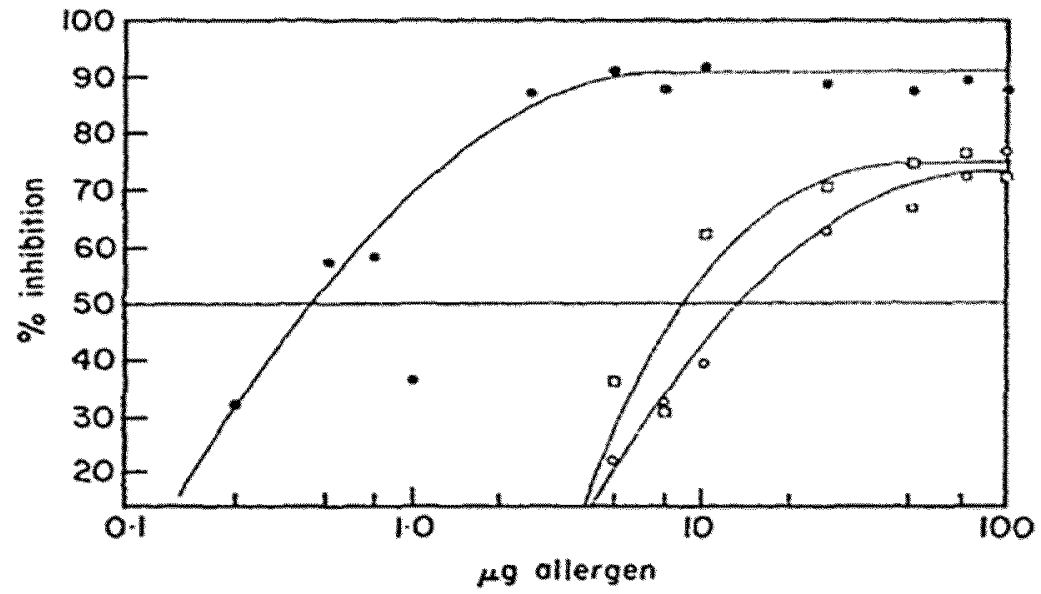

Fig. 1. Inhibition of house dust RAST by different house dust preparations. $\bullet: R_{1}, \square: R_{2}, 0: R_{4}$ Serum 77944 of a highly dust allergic patient, associated with animal dander allergy was used. Trmal $1 g E: 215$ i.u. $\mathrm{ml}^{-1}$. RAST (in $\%$ binding of added radio-activity): house dust $R_{1}: 28 \cdot 1 \%$, cat daruder: $33 \cdot 1 \%$; $R$,-coupled discs were used.

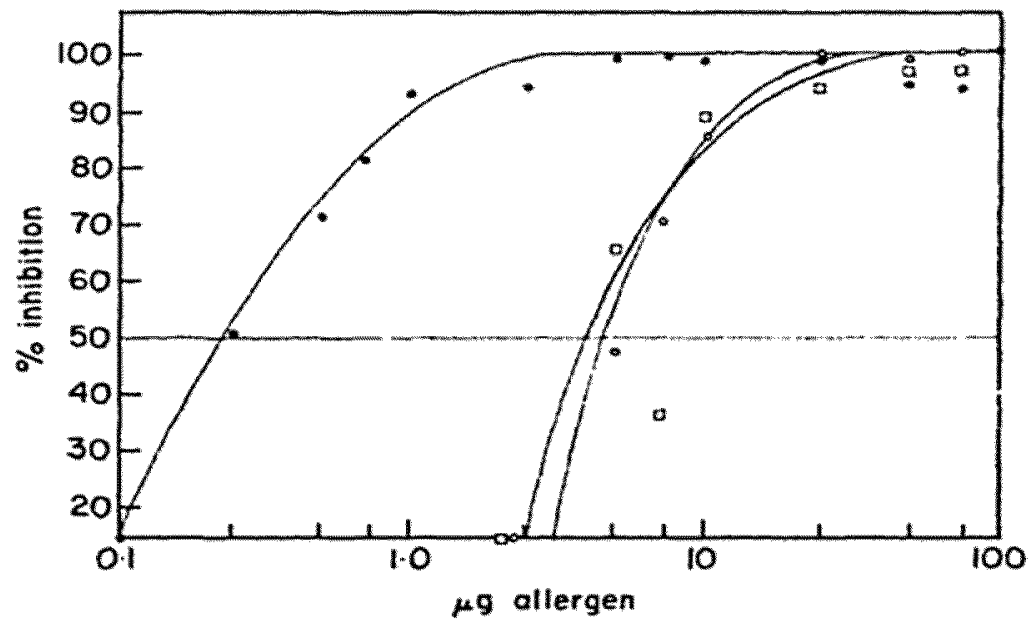

Fig. 2. Conditions as given in the legend to Fig. 1, except that $R_{4}$-coupled discs were used. 


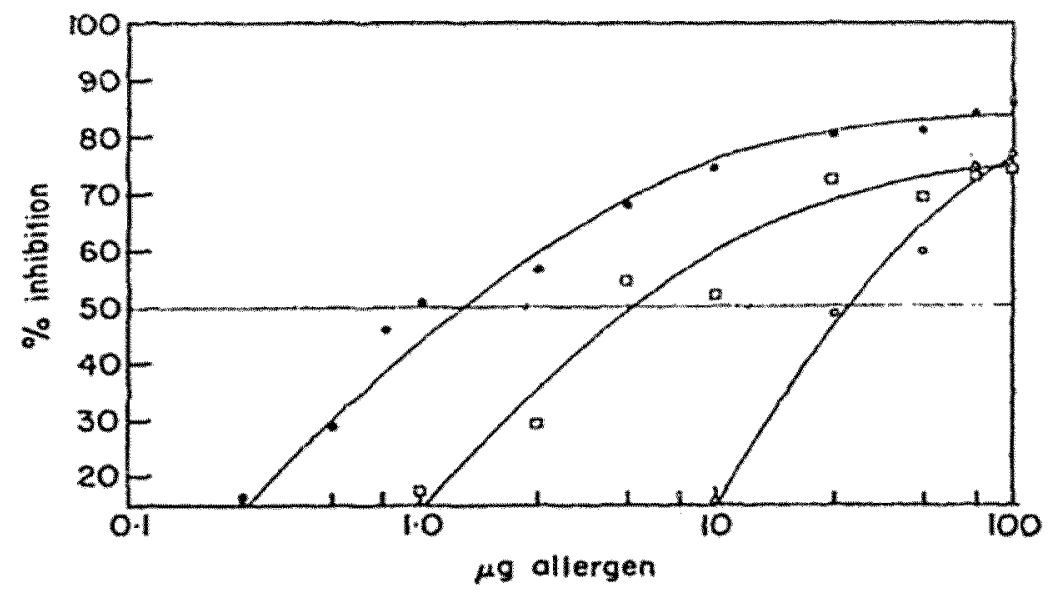

Fig. 3. Inhibition of house dust RAST with serum 77951 (atopic asthma, total $\mathrm{IgE} 1170 \mathrm{i} . \mathrm{u} . \mathrm{ml}^{-1}$, RAST house dust $R_{1}: 37 \cdot 4 \%$, cat dander: $35-4 \%$, dog dander $3 \cdot 7 \%$, borse dander $2 \cdot 9 \%$ ); $R_{1}$-coupled discs were -used.

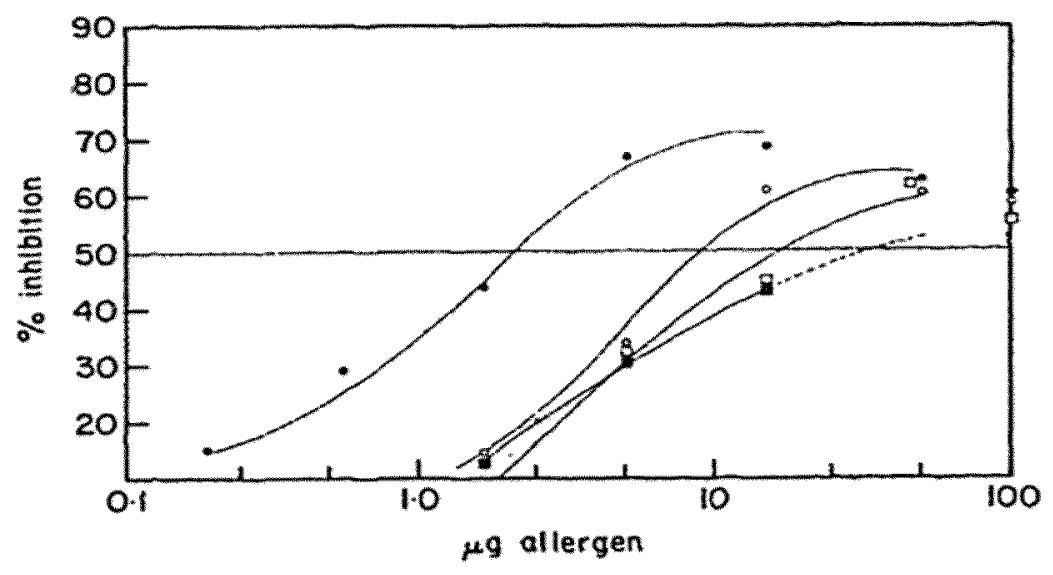

Fig. 4. Inhibition curves with a 1:8 diluted serum pool of 15 samples from highly allergic subjects (total IgE: 3800 i.u. $\mathrm{ml}^{-1}$, RAST house dust $R_{1}: 31 \cdot 9 \% ; R_{1}$-coupled discs were used. $\bullet: R_{1}, \square: R_{2}, \ldots: R_{3}$, $0: R_{*}$.

allergic pacients. The porency sequences here was established as $R_{1}>R_{4}>R_{2}>R_{3}$, using $R_{1}$ discs. Interestingly, exactly the same sequence was reported back from the London laboratory, using a British serum pool and $\mathrm{GP}_{\mathrm{P}}$ discs. Working with a serum pool, we found these results highly reproducible on various occasions. In these experiments it was, moreover, again demonstrated that the results apparently did not depend on the allergen preparation coupled to the discs.

In order to evaluate the results in quantitative terms, the $50 \%$ inhibition points were established graphically. The numerical data, collectively listed in Table 2, demonstrate that, $c$ ven though the potency sequences are similar, large differences are observed with different sera, even among different serum pools. If, for purposes of standardization, one allergen preparation is arbitrarily chosen for reference, the potency ratios among various products - as shown in Table 3-become very hard to interpret.

\section{Skin test results}

The results of intracutaneous tests with $R_{1}, R_{2}, R_{3}$ and $R_{4}$ in a randomized group of house-dust sensitive patients showed that this group could be divided into so-called 
TABLE 2. Relative potencies of house dust preparations. $R_{1}, R_{2}, R_{33}, R_{4}$, and $\mathrm{G}_{p_{1}}$ as determined by RAST inhibition, in $\mu \mathrm{g}$ of product giving $50 \%$ inhibition in a standard assay

\begin{tabular}{|c|c|c|c|c|c|c|c|}
\hline \multirow[b]{2}{*}{ Product } & \multicolumn{2}{|c|}{77944} & \multirow{2}{*}{$\begin{array}{c}77951 \\
R_{1}\end{array}$} & \multirow{2}{*}{$\begin{array}{c}\text { Pool } A \\
R_{1}\end{array}$} & \multirow{2}{*}{$\begin{array}{c}\text { Pool B } \\
R_{1}\end{array}$} & \multirow{2}{*}{$\begin{array}{l}\text { Pool } \\
\text { London } \\
\text { Gpl }_{1}\end{array}$} & \multirow{2}{*}{$\begin{array}{l}\text { Serum } \\
\text { disc }\end{array}$} \\
\hline & $R_{k}$ & $R_{4}$ & & & & & \\
\hline$R_{1}$ & 0.44 & $0 \cdot 23$ & $1 \cdot 4$ & $2 \cdot 1$ & $2 \cdot 0$ & $2 \cdot 6$ & \\
\hline$R_{2}$ & $8 \cdot 2$ & $4 \cdot 0$ & $5 \cdot 4$ & $17 \cdot 2$ & $26 \cdot 0$ & $7 \cdot 2$ & \\
\hline$R_{3}$ & n.d. & n.d. & n.d. & 31.0 & n.d. & $>100$ & \\
\hline$R_{4}$ & $12 \cdot 5$ & $4 \cdot 6$ & 28.0 & 10.0 & $13 \cdot 5$ & 6.8 & \\
\hline
\end{tabular}

TABLE 3. Potency ratios in RAST inhibition of various $R$-preparations, arbitrarily calculated with the $R_{1}$-reference as unity

\begin{tabular}{llllllll}
\hline Product & \multicolumn{2}{c}{77944} & 77951 & Pool A \\
$R_{1}$ & $R_{4}$ & $R_{1}$ & $R_{1}$ & $\begin{array}{c}\text { Pool B } \\
R_{1}\end{array}$ & $\begin{array}{c}\text { Pool } \\
\text { Londun } \\
\text { Gpi }\end{array}$ & $\begin{array}{c}\text { Serum } \\
\text { disc }\end{array}$ \\
\hline$R_{1}$ & 1.0 & 1.0 & 1.0 & 1.0 & 1.0 & 1.0 \\
$R_{2}$ & 0.05 & 0.06 & 0.26 & 0.12 & 0.08 & 0.37 \\
$R_{3}$ & n.d. & n.d. & n.d. & 0.07 & n.d. & 0.02 \\
$R_{4}$ & 0.04 & 0.05 & 0.05 & 0.21 & 0.15 & 0.38 & \\
\hline
\end{tabular}

TABLE 4. Relative potency of house dust preparations $R_{1}, R_{2}, R_{3}$ and $R_{4}$ in skin testing (threshold values from end point titrations in a group of 16 parients, $\mu \mathrm{g} \mathrm{ml}^{-1}$ ) compared to relative potencies in RAST inhibition (mean of two serum pools, $R_{1}$-discs; $\mu \mathrm{g}$ for $50 \%$ inhibition). Reference $R_{1}$ arbitrarily raken as unity

\begin{tabular}{ccc}
\hline Preparation & Skin tests & RAST inhibition \\
\hline$R_{1}$ & 1.0 & 1.0 \\
$R_{2}$ & 0.05 & 0.1 \\
$R_{3}$ & 0.1 & 0.03 \\
$R_{4}$ & 1.5 & 0.15 \\
\hline
\end{tabular}

strong and weak reactors. The strong reactors responded with wheal and flare reactions to a much lower allergen concentration $\left(0.04 \mu \mathrm{g} R, \mathrm{ml}^{-1}\right)$ than the weak reactors. Although the dose-response curves for skin titration in 10-fold serial dilutions differed among (16) individual patients, the difference in allergen reactivity among the groups of strong and weak reactors was about 100 fold for $R_{1}, 30$ fold for $R_{2}$ and 300 fold for $R_{33}$. For comparison of the relative potencies of the different house-dust extracts, only the results obtained in the strong reactors have been used here, because preparation $R_{4}$ was not investigated in the weak reactors. The potencies were evaluated as the mean $(n=16)$ concentration in the group from end point titration (i.e. a $7 \mathrm{~mm}$ diameter wheal size). The value of $R$, was arbitrarily converted to unity, in order to establish the potency ratio of the four allergen preparations. The results are shown in Table 4 . A more detailed account of the in vivo results will be given in a separate communication. 
No attempts have been published so far to standardize the widely used, but chemically poorly defined house dust allergens by means of the RAST-inhibition technique. Although the poor correlation reported between in vitn skin test results and in vitro direct RAST assay in house dust allergy was not encouraging, it was decided to examine RAST inhibition as part of an extensive multicenter program on the standardization of house dust extracts.

The results obtained by RAST-inhibition with four different reference preparations showed that the method was reproducible, but not very accurate. Duplicate determinations often showed large variations, which could not be attributed to unequally charged paper discs, because direct RAST assays with these discs showed only small intra-assay variance (about $5 \%$ ). The cause for this has not been elucidated. However, it has recently been suggested that IgE binding to house dust may be indirect (Berrens, Guikers \& Bruynzcel, 1979), so that interference by unknown serum factors may strongly influence the results of RAST inhibition. This might well explain the different maxima of RAST inhibition observed with the individual sera and the serum pools.

Comparison of the results with the individual sera and the pools brings out one of the most striking effects of RAST-inhibition. Although with one serum and with the pools an almost identical potency sequence was found $\left(R_{1}>R_{4}>R_{2}>R_{3}\right)$, the sequence in serum 77951 deviated $\left(R_{1}>R_{2}>R_{4}\right)$. Furthermore, in one other individual serum sample, not presented here, the entirely different sequence $R_{2}>R_{4}>R_{1}$ was observed. This illustrates the serious drawback of using a pool of sera in RAST inhibition, because in a mixture the individual serum characteristics are masked by dilution. On the other hand, a serum pool has the advantage of featuring a large diversity of antibody specificities. Results obtained with such a serum pool for the standardization of an allergenic preparation may, however, not be representative for its subsequent application in individual patients.

Skin tests with the different house dust preparations revealed that house dust allergic patients could be classed as either strong or weak reactors. In each group the doseresponse curves for skin-titration differed from one patient to another. This indicates that particular characteristics of individual patients were being established rather than characteristics of the allergenic preparations. An entirely similar conclusion was reached by Sherago, Berkowitz \& Reitman (1950), who evaluated the results of a much more extended program of house dust allergen standardization, sponsored at the time by the American College of Allergists. From the averaged results among the group of strong reactors, however, a sequence of relative potencies was roughly established, but this did not coincide sat isfactorily with the sequence determined by RAST inhibition (Table 4). Furthermore, the sequence obtained by skin-testing also depended on the method of evaluarion, as will be discussed elsewhere (Kersten et al., in prep.).

In an attempt to standardize ragweed pollen extracts by skin testing, Arbesmanet al. (1977) found this method unsuitable because of large variation in the reaction pattern among individual parients. By means of RAST inhibition, using a pool of sera of highly ragweed allergic patients, they were then able to establish the relative potencies of different ragweed extracts based on the Ar.tigen E content. Amazingly, RAST inhibition was then proposed as an in vitro standardization of ragweed extracts, despite the fact that the ir own results showed it to have poor clinical relevancy. The results of these authors-like ours with house dust extracts-strongly suggest that mechanisms other than those mediated by $\lg \mathrm{E}$ must be involved in tivo. 
An unexpected-and ununderstood -outcome of the present studies was that the potency sequence in RAST inbibition apparently did not depend on the origin or exrent of purification of the allergen batch insolubilized on the discs. Furthermore, the observation that the most highly purified preparation, $R_{\text {. }}$, although more accive than its parent product $R_{2}$, was not the most potent of the series, underlines the previous recommendacion nor to push purificicion too far for extracts to be used in allergy practice (Berrens, 1971 ).

We do not consider it a disadvantage that the serum pools did not come from the patients actually skin-tested with preparations not collected within their own area. If standardization is going to be imposect on allergen producers, this is probably the practical situation they will have to face.

It has repeatedly been pointed out that, in house dust allergy, mechanisms other than antibody-mediaced reactions must be involved (Berrens, 1974; Berrens, Schoonenwolf \& Bruynzeel, 1978). One of these mechanisms is reflected in the observed in vitro complement consumption by house dust allergens; on this basis, an independent method of allergen standardization has been developed (Berrens \& Guikers, 1975). The technique has also been applied in this study on $R_{1}-R_{4}$ preparations. Surprisingly, the potency sequence observed with this method roughly ran parallel to the RAST-inhibition data presented here. These results will be discussed in more detail in a subsequent commurication.

\section{Acknowledgements}

The authors are indebted to Mr C. L. H. Guikers and Mr W. van den Boogaard for skilled technical assistance. Mr G. T. Hoek (Haarlems Allergenen Laboratorium b.v., Haarlem, The Netherlands) kindly provided the $R_{1}$-preparation. The $R_{3}$ - preparation was donated by $D r$ E. H. Relyveld (Institur Pasteur, Garches, France). We are greatly indebted to Dr W. D. Brighton, National Institure for Biological Standards and Control, London (England), for submitting his preliminary RAST-inhibition results. The initiation of this work was encouraged by the Paul Ehrlich Institute, Frankfurt am Main (Federal Republic of Germany) and by the Foundation Study Centre for Allergy Projects, Amsterdam (The Netherlands).

\section{REFERENCES}

Aas, K. \& Johansson, S. G. O. (1971). The radioallergosorbent test in the in vitro diagnosis of multiple reaginic allergy. Journal of Allergy and Clinical Immunology 48, 134-142.

Arbesman, C. E. \& Eagle, H. (1939). The assay of ragweed pollen extracts.Journal of Allergy 10 , $521-536$.

Arbesman, C. E., Wypych, J. 1. \& Reisman, R. E. (1977). Evaluation of RAST inhibition as a method for the standardization of ragweed pollen extracts. International A rhites of Allergy and Applied Immunology 53, 310-318.

Berrens, L. (1970). The allergens in house dust. Progress in Allergy 14, 259-339.

Berrens, L. (1971). Introduction to round table conference on allergen standardization. Internasional Archites of Allergy and Applied I mmonology 41, 222-230.

Berrens, L. (1974). Inhalant allergens in human atopic diseases: their chemistry and modes of acrion. Annals of the New York Academy of Sciences 221, 183-198

Berrens, L. \& Guikers, C. L. H. (1975). Value of fluid phase complement consumption as a means of in vitro allergen standardization. Procedings of the IABS-W/HO Symposium on the Standardization and Control of Allergens Administered to Man. Geneta. pp. 235-248. Basel: Karger.

Berrens, L., Schoonenwolf, D. A. \& Bruynzeel, P. L. B. (1978). Complement consumprion and 
IgE binding by house dust allergen in the serum of atopic pationts. Allergologia et lmmunopistolages 6. 45-5.4.

Berrens, L.. Guikers, C. L. H. B Braynzeel, P. L. B. (1979). Possible indirect binding of lgE in house dust RAST. Antets of Allergy $43,38-43$.

Brighton. W. D. \& Topping. M. D. (1977). Standards from house dust, in: Allergy and Clinical Immunolok. Procedings IXtb Internationsl Congress of Allergology, Bwenos Aircs 1976 , Excerpla Aledica International Congress Series $414,161-166$.

Ceska, M.. Ericksson, R. \& Varga, J. M. (1972). Radioimmunosorbenr assay of allergens. Joumal of Allergy and Clinical Immanology 49, $1-9$.

Gleich, G. J., Larson, J. B., Jones, R. J. \& Baet, H. (1974). Measurement of the potency of allergy extracss by their inhibitory capacities in the sadioallergosorbent rest. Jourmat of Allergy and Clinical Immunology $53,158-169$.

Hogarth-Scott, R. S., MeNicol, R. N., Williams, H. E. \& Johansson, S. G. O. (1973). Diagnosis of allergy in witro: a comparison between skin-sensicivity testing and serum levels of specific IgE antibody in children. Medical Journal of Autralita 1, 1293-1297.

Kerscen, W. (1978). Die Korrelation von Hauttest-Provokations-test-RAST (Radio-AllergoSorbent-Test) beim Hausstaub-allergen. Allergologie 1, 81-86.

Laroche. C., Ky, N.-T., Relyveid, E. H. \& Roche, L. (1967). Traitement de l'allergie respiratoire par une préparation retard d"extrair de poussière de maison ad̉sorbée sur hydroxyde dalumine. Etude préliminaire sur 30 cas. La Presse Médicale 75, 2667-2669.

Pascual. H. C., Mohan Reddy, P., Nagaya, H., Lee, S. K., Lauridsen, J., Gupta, S. \& Jerome, D. (1977). Agreement berween radio-allergosorbent test and skin test. Annals of Allergy 39 , $325-327$.

Scherago. M. Berkowitz, B. \& Reitman. M. (1950). Standardization of dust extracts. 1. Srandardization on the basis of equal molecular size. Annals of Allergy 8, 437-452.

Wide, L. . Bennich, H. \& Johansson, 5. G. O. (1967). Diagnosis of allergy by an in virro test for allergen antibodies. Laneet ii, $1105-1107$.

Wüthrich, B. \& Kopper, E. (1975). Nachweis von spezifischen IgE-Serumantikörpern mit dem Radio-Allergo-Sorbent Test (RAST) und seine Bedeutung für die Diagnostik der atopischen Allergie. Schuvizerische Nediziniscbe Wochenschrift 105, 1337-1345.

Yman, L., Ponterius, G. \& Brandt, R. (1975). RAST-based allergen assay methods. Proceedings of the LABS-WrHO Symposizm on the Slandardization and Control of Allergens Administered to Man. Genet a. pp. 151-165. Basel: Karger. 